\title{
Patterns of Coronary Artery lesion in a Patient with Chronic Obstructive Pulmonary Disease, Presenting with an Acute Coronary Syndrome
}

\author{
Ranjit Sharma*, Anish Hirachan, Milan Gautam \\ Department of cardiology, Nepal Mediciti, Lalitpur, Nepal
}

*Corresponding Author: Ranjit Sharma Nepal Mediciti hospital, 44700 Bhaisepati, Lalitpur, Nepal

Received Date: Augusł 03, 2021; Accepted Date: Augusł 16, 2021; Published Date: August 20, 2021

Citation: Ranjit Sharma, Anish Hirachan, Milan Gautam, (2021) Patterns of Coronary Artery lesion in a Patient with Chronic Obstructive Pulmonary Disease, Presenting with an Acute Coronary Syndrome. J. Clinical Cardiology and Cardiovascular Interventions, 4(14); Doi:10.31579/2641-0419/210

Copyright: () 2021 Ranjit Kumar Sharma, This is an open-access article distributed under the terms of the Creative Commons Attribution License, which permits unrestricted use, distribution, and reproduction in any medium, provided the original author and source are credited.

\begin{abstract}
Background: This study was designed to evaluate the patterns of coronary artery disease in patients with chronic obstructive pulmonary disease (COPD) presenting with the acute coronary syndrome (ACS).

Methods: This was a prospective, observational study, conducted on 69 patients with chronic obstructive pulmonary disease, presenting with acute coronary syndrome undergoing coronary angiogram from September 2017 to March 2021 . All patients had undergone coronary angiogram; severity and morphology of lesion as well as the severity of calcium were analyzed.

Results: The study showed that 69 patients with COPD who presented with ACS, $58.8 \%$ of patients were presented with NSTEMI, 30.2\% STEMI and Unstable angina 11\%. The average time of presentation after the onset of the symptom was 17.6 hours. $64 \%$ of patients were a smoker. Coronary involvement $10 \%$ of patients had LM, 50\% TVD, 30\% DVD, and $10 \%$ had SVD. Type a coronary lesion was seen in 5\%, Type B in $20 \%$, and Type C in $75 \%$ of patients. Mild Coronary calcium was seen in $25 \%$. Moderate calcium was in $40 \%$ and severe calcium in $35 \%$.

Conclusions: COPD patients presenting with ACS, associated with increased severity of coronary calcium and coronary lesions.
\end{abstract}

Keywords: acute coronary syndrome; pulmonary disease; chronic obstructive pulmonary disease

\section{Introduction}

Acute coronary syndromes (ACS) and chronic obstructive pulmonary disease (COPD) are leading causes of death and disability worldwide [1]. World Health Organization data show that around 17.7 million cardiovascular disease deaths worldwide in 2015 (31\% of all-cause mortality), of whom 7.4 million were due to coronary artery disease [2]. At the same time, COPD is the fourth leading cause of mortality globally, affecting more than 210 million people [3]. The Global Initiative for Chronic Obstructive Lung Disease (GOLD) defines COPD as a disease characterized by persistent and usually progressive airflow [4]. Several pathological mechanisms underlie the relationship between COPD and ischemic heart disease [5]. First, COPD and ischemic heart disease share common risk factors, of which smoking and increasing age are most important [6]. Moreover, the prevalence of other cardiovascular risk factors such as diabetes and hypertension seems to be higher in COPD patients compared to healthy individuals [7].

Atherosclerosis is a lipid-related chronic inflammatory disease in which immune mechanisms play a pivotal role [8]. The lesions are filled with large numbers of immune cells. Similarly, chronic obstructive pulmonary disease (COPD) is characterized by an intense inflammatory process in the airways, parenchyma, and pulmonary vasculature. Systemic inflammation, because it plays a central role in the pathogenesis of atherosclerosis and COPD, could be a pathophysiological link between them [9]. However, there is still no consensus in the literature because COPD was considered to be a predictor of CAD and increased cardiovascular risk in some studies, whereas other studies did not [10]. However, the open question is whether COPD and cardiac disorders are linked beyond these risk factors. Altered, persistent, and low-grade systemic inflammation likely plays a role: raised inflammatory markers, such as C-reactive protein and different cytokines, have been repeatedly related to atherosclerosis and subsequent ischemic heart disease (IHD), $\mathrm{HF}$, and AF [11]. Such inflammatory markers are raised in many patients with COPD. Furthermore, exacerbation frequency in COPD relates to higher levels of inflammation and a higher risk of MI [12]. The most established hypothesis explaining the interaction of COPD and ACS is the inflammation model. The inflammation model hypothesizes that the local airway inflammation in COPD "spills over" into the systemic circulation and the coronary arteries, promoting coronary plaque development, perhaps explaining why CAD is highly prevalent in COPD [13]. Another 
potential contributor to the association between COPD and ACS is the dysregulation and over-activation of the sympathetic nervous system. COPD patient's exhibit reduced heart rate variability, increased norepinephrine turnover, and increased plasma levels of renin, all signs of increased sympathetic nervous system activity, also known to be harmful in CAD [14].

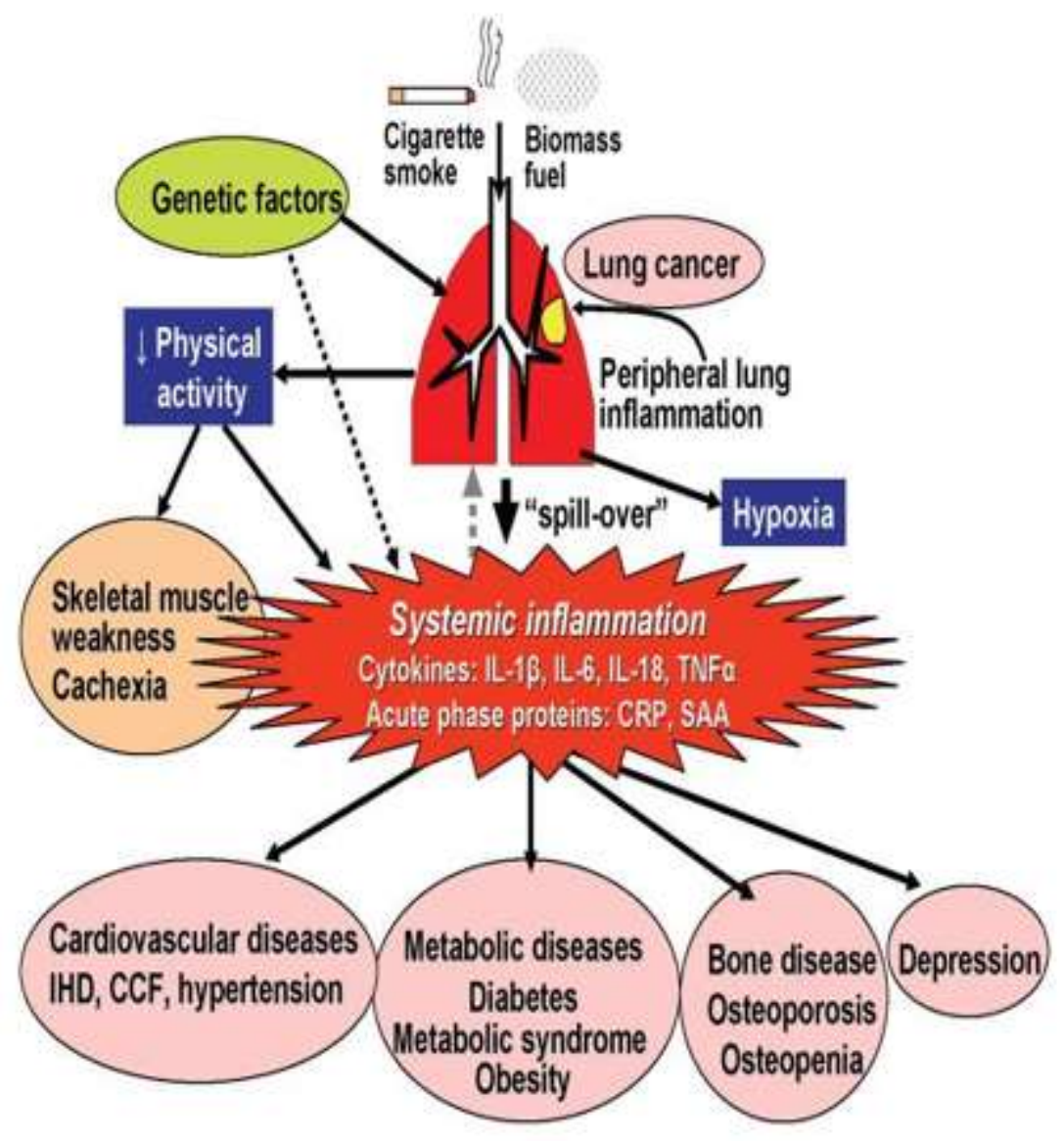

Figure 1: Diagram representing how inflammation in chronic obstructive pulmonary disease may 'spill over into the systemic circulation and increase the risk of several diseases including cardiovascular disease. Original image from Barnes

\section{Methods}

It is a retrospective, single-center study, performed at Nepal Mediciti Hospital, Nepal. All the COPD patients who presented with acute coronary syndrome from September 2017 to March 2021 were enrolled in this study. All 69 patients with COPD, presenting an acute coronary syndrome were taken to the catheterization lab for a coronary angiogram. The severity and morphology of the lesion as well as severity of calcium were analyzed. Calcification was identified as readily apparent radiopacities within the vascular wall at the site of the stenosis and was classified as none/mild, moderate (radiopacities noted only during the cardiac cycle before contrast injection), and severe (radiopacities noted without cardiac motion before contrast injection generally compromising both sides of the arterial lumen) [15]. ACC/AHA classification of coronary lesions is a system used to classify coronary arterial calcific plaque burden. It is classified as [16]

\section{Type A}

1. Discrete $(<10 \mathrm{~mm})$ 2.Concentric 3.Nonangulated segment $<45^{\circ}$ 4. Smooth contour 5.little or no calcification 6.less than totally occlusive 7. Not ostial in location 8. No major branch involvement 9.Absence of thrombus

Type B
1. Tubular (10-20 mm) 2.Eccentric 3.moderate tortuosity of proximal segment 4.Moderately angulated, $45-90^{\circ}$ 5.Irregular contour 6.Moderate to heavy calcification 7.Ostial in location.

8. Bifurcation lesions requiring double guidewires 9.Some thrombus present 10. This can be subclassified into two subcategories

\section{Type C}

1. Diffuse 2. Excessive tortuosity of proximal segment 3. Extremely angulated, $>90^{\circ}$ 4.Inability to protect major side branch 5. Degenerated vein graft with friable lesions.

\section{Results}

A total of 69 COPD patients presenting with acute coronary syndrome were included in the study. The average age was $59.9 \pm 8.5$ with the youngest being 32 years and the oldest being 88 years old. Most of the patients were male $76 \%$.

The commonest symptom was chest pain $57 \%$ followed by shortness of breath in $43 \%$. The diagnosis was made base on a clinical symptom, electrocardiography findings, and cardiac biomarkers. Most of the patients 41(58.8\%), were presented with NSTMI, followed by $21(30.2 \%)$ STEMI and 7(11\%) Unstable angina. Among the risk factors, smoking 
was the commonest and found in $64 \%$ of patients followed by hypertension $52 \%$ and diabetic 53\%. Angiography showed $10 \%$ of patients had LM, 50\% TVD, 30\% DVD, and 10\% of patients had SVD. ACC/AHA classification of coronary lesions is a system used to classify coronary arterial calcific plaque burden. Based on this classification Type
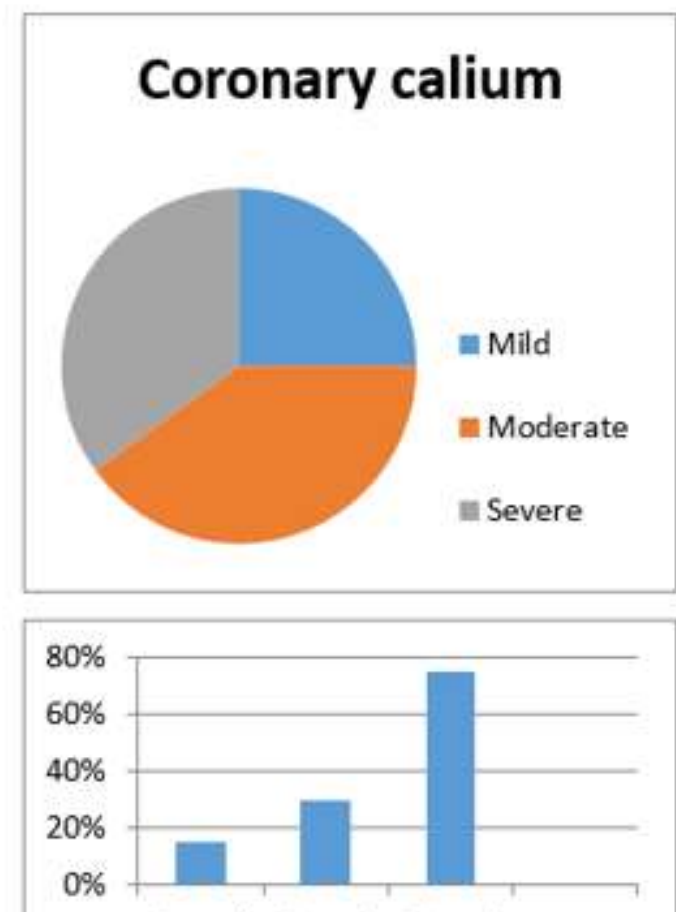

Type A Type B Type C

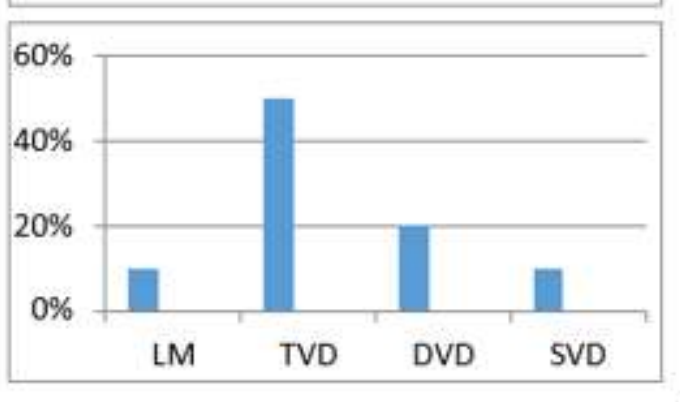

a coronary lesion was seen in 5\%, Type B in $20 \%$, and Type C in $75 \%$ of patients. Based on angiographic findings coronary calcium was classified into mild, moderate, and severe. Mild Coronary calcium was seen in $25 \%$. Moderate calcium was in $40 \%$ and severe calcium in $35 \%$.

Table 1: Baseline characteristics of the study subjects

\section{Discussion}

Several pathological mechanisms underlie the relationship between COPD and ischemic heart disease. ACS and COPD have shared risk factors that may contribute substantially to the relationship between the diseases; the most important are smoking and high age. Even passive smoking increases the risks of both ACS and COPD. There is substantial evidence that inflammation plays a key role in the development of both COPD and CAD.

Igor LM et al found that in patients with suspected CAD, comorbid COPD was associated with increased severity and extent of coronary lesions, calcific plaques, and elevated calcium score independent of the established risk factors for CAD (4). In addition, the more severe the COPD, the greater the severity of coronary lesions and calcification present. Roversi et al reported that $88.1 \%$ of the patients had coronary lesions (CAD), and $71.3 \%$ of obstructive coronary lesions $(\geq 50 \%$ of the vessel) occurred in patients with COPD. The prevalence of proven CAD

\begin{tabular}{|l|c|}
\hline Age (years) & $59.9 \pm 8.5$ \\
Sex & $53(76 \%)$ \\
Male & $16(24 \%)$ \\
female & $17.6(20 \mathrm{~min}-10$ days) \\
Duration of symptom/s & \\
& \\
Risk factors & $35 \%$ \\
Diabetes Mellitus & $52 \%$ \\
Hypertension & $64 \%$ \\
Smoking & $25 \%$ \\
Dyslipidemia & $5 \%$ \\
Family h/o of CAD & \\
& \\
Presenting symptom/s: & $57 \%$ \\
Chest pain & $43 \%$ \\
Shortness of breath & \\
& \\
Diagnosis: & $41(58.8 \%)$ \\
NSTEMI & $21(30.2 \%)$ \\
STEMI & $7(11 \%)$ \\
Unstable Angina & \\
& \\
\hline
\end{tabular}

in patients with COPD is known and ranges from $47 \%$ to $60 \%$ [17]. Similar findings were found in our study and showed that most of the patients presented with NSTEMI about $58.8 \%$ and with multivessel involvement. Tripel vessel disease was almost $50 \%$.

Baty $\mathrm{F}$ et al reported that the frequent occurrence of stenosis, severe lesions, and markedly calcified coronary plaques, especially in the global Initiative for Obstructive Lung Disease stages III group and also reinforces that the inflammatory processes of COPD do not participate only in the formation of atherosclerotic plaques but also in their progression $[18,19]$. Similar findings were found in our study Type A coronary lesion was seen in 5\%, Type B in $20 \%$, and Type C in $75 \%$ of patients.

Williams et al found higher Coronary calcium in COPD patients and associated dyspnea and reduced exercise capacity, data coincident with our study where patients with COPD had higher and more frequent 
Coronary calcium [20]. In our study, Severe calcium was found in $35 \%$ and moderate in $40 \%$.

\section{Study limitations}

There are several limitations of this study. First, it is a single-center retrospective study. Second IVUS and OCT were not used to interrogate the coronary lesion.

\section{Conclusion}

In COPD patients presented with ACS is associated with increased severity and extent of coronary lesions, calcific plaques, and elevated calcium scores, independent of the traditional risk factors for established $\mathrm{CAD}$. The more advanced the COPD, the greater the coronary lesions and calcification.

\section{References}

1. Chen W, Thomas J, Sadatsafavi M, et al. Risk of cardiovascular comorbidity in patients with chronic obstructive pulmonary disease: a systematic review and meta-analysis. Lancet Respir Med 2015; 3: 631-639.

2. World Health Organization [webpage on the Internet]. Cardiovascular Disease. 2016. [2016; cited 2016 Set]; Available from: http://www. who.int/cardiovascular_diseases/en.

3. Diaz-Guzman E, Mannino DM. Epidemiology and prevalence of the chronic obstructive pulmonary disease. Clin Chest Med. 2014; 35(1):7-16.

4. Igor Lm, Antônio Cs, Maria LD, et al. Coronary lesions in patients with COPD (Global Initiative for Obstructive lung Disease stages I-III) and suspected or confirmed coronary arterial disease. International Journal of COPD 2018:13 1999200.

5. Smith MC, Wrobel JP. Epidemiology and clinical impact of major comorbidities in patients with COPD. Int J Chron Obstruct Pulmon Dis. 2014; 9:871-888.

6. Papaioannou AI, Bartziokas K, Loukides S, et al. Cardiovascular comorbidities in hospitalized COPD patients: a determinant of future risk? Eur Respir J. 2015; 46(3):846-849.

7. Hasan A, Ansari N, Parvez A, Beg M, Bhargava R. Understanding the relation between COPD and coronary artery disease. J Indian Acad Clin Med. 2014; 15(2):120-124.

8. S ranjit, Li da chu et al. Potential role of dendritic cells for progression of atherosclerotic lesions. Postgrad Med J 2006; 82:573-575.

9. MacNee W. Systemic inflammatory biomarkers and comorbidities of chronic obstructive pulmonary disease. Ann Med 2013; 45: 291-300.
10. Hawkins NM, Huang Z, Pieper KS, et al. Chronic obstructive pulmonary disease is an independent predictor of death but not atherosclerotic events in patients with myocardial infarction: analysis of the Valsartan in Acute Myocardial Infarction Trial (VALIANT). Eur J Heart Fail 2009; 11: 292-298.

11. Barnes PJ. Inflammatory mechanisms in patients with chronic obstructive pulmonary disease. J Allergy Clin Immunol. 2016; 138(1):16-27.

12. Wedzicha JA, Seemungal TA, MacCallum PK, et al. Acute exacerbations of chronic obstructive pulmonary disease is accompanied by elevations of plasma fibrinogen and serum IL6 levels. Thromb Haemost 2000; 84: 210-215.

13. de Lucas-Ramos P, Izquierdo-Alonso JL, Moro JMR-G, et al. CONSISTE Study Group. Chronic obstructive pulmonary disease as a cardiovascular risk factor. Results of a case-control study (CONSISTE study). Int J Chron Obstruct Pulmon Dis. 2012; 7:679-686.

14. Sin DD. Why are patients with chronic obstructive pulmonary disease at increased risk of cardiovascular diseases? The potential role of systemic inflammation in chronic obstructive pulmonary disease. Circulation 2003; 107: 1514-1519.

15. Popma J, Bashore T. Qualitative and quantitative angiography. In: Topol E, ed. Interventional Cardiology. Philadelphia, Pa: WB Saunders; 1993; 1:1052-1068.

16. Ryan TJ, Faxon DP, Gunnar RM, Kennedy JW, King SB III, Loop FD, Peterson KL, Reeves TJ, Williams DO, Winters WL $\mathrm{Jr}$, et al. Guidelines for percutaneous transluminal coronary angioplasty. A report of the American College of Cardiology/American Heart Association Task Force on Assessment of Diagnostic and Therapeutic Cardiovascular Procedures (Subcommittee on Percutaneous Transluminal Coronary Angioplasty). Circulation 1988; 78:486-502.

17. Roversi S, Roversi P, Spadafora G, Rossi R, Fabbri LM. Coronary artery disease is concomitant with chronic obstructive pulmonary disease. Eur J Clin Invest. 2014;44(1):93-102.

18. Baty F, Putora PM, Isenring B, Blum $T$, Brutsche $M$. Comorbidities and burden of COPD: a population-based casecontrol study. PLoS One. 2013;8(5):e63285.

19. Bhatt SP, Dransfield MT. Chronic obstructive pulmonary disease and cardiovascular disease. Transl Res. 2013; 162(4):237-251.

20. Williams MC, Murchison JT, Edwards LD, et al. Coronary artery calcification is increased in patients with COPD and associated with increased morbidity and mortality. Thorax. 2014; 69(8):718-723. 
(cc) (†)

This work is licensed under Creative

Commons Attribution 4.0 License

To Submit Your Article Click Here: Submit Manuscript

DOI:10.31579/2641-0419/210
Ready to submit your research? Choose Auctores and benefit from:

* fast, convenient online submission

* rigorous peer review by experienced research in your field

* rapid publication on acceptance

* authors retain copyrights

* unique DOI for all articles

* immediate, unrestricted online access

At Auctores, research is always in progress.

Learn more www.auctoresonline.org/journals/clinical-cardiology-andcardiovascular-interventions 